\title{
Calving difficulty in dairy cows has a longer effect on saleable milk yield than on estimated milk production
}

\author{
A. C. Barrier ${ }^{1}$ and M. J. Haskell \\ Sustainable Livestock Systems, Scottish Agricultural College, Edinburgh, EH9 3JG, United Kingdom
}

\begin{abstract}
A difficult calving affects the welfare of the cow and has economic implications for the farm. The degree of calving difficulty can vary from no assistance needed through a slight pull required to surgery being needed. With respect to milk production, it is not clear at which degree of calving difficulty adverse effects occur or for how long they last. Studies usually only consider the milk produced by animals who completed full lactations but the saleable milk production of the whole herd, regardless of each cow having achieved a full lactation, might be a better indicator of the productivity of the cows and the underlying stresses they experience, as well as being more representative of the real losses that producers incur. The objective of this study was to investigate how various degrees of calving difficulty would alter both the cow's milk production and their production of saleable milk over different stages of their subsequent lactation. The calving difficulty scores and the subsequent milk production were retrieved from an experimental dairy farm (in the United Kingdom) for 2 herds that contained 2,430 and 1,413 lactations. To account for milk saleable by the farmer, individual cumulative saleable milk yields, referred to as saleable milk yields (SMY), were calculated at 30, 60, 90, and $300 \mathrm{~d}$ in milk unconditional on the animal having achieved the lactation stage of interest. Lactation SMY were obtained based on the real lactation length achieved by the animal. Mean daily milk yields were also calculated for the same lactation stages as an estimate of the cow's milk production (CMP). Calving difficulty impaired milk production of dairy cows in terms of CMP and SMY in both herds, highlighting impaired income for dairy producers as well as detrimental effects to the productivity of the cows and potentially impaired health and survival. The management of the herd affected the presence of an effect of each degree of difficulty on SMY and CMP as well as its magnitude and duration. The analysis of SMY, independently of
\end{abstract}

Received July 22, 2010.

Accepted January 7, 2011.

${ }^{1}$ Corresponding author: alice.barrier@sac.ac.uk each animal having achieved a full lactation, could be a more sensitive indicator of the subsequent long-lasting biological stresses than CMP alone.

Key words: dairy cow, calving difficulty, milk production, dystocia

\section{INTRODUCTION}

Parturition is intimately interlocked with lactogenesis in all mammals. In dairy cows, it marks the start of the lactation and therefore the beginning of the productive cycle. However, it is also a high-risk time for both mother and offspring. Calving difficulty, also known as dystocia, often means that assistance must be provided during delivery. The grading of the amount of assistance required is therefore a widely used measure to identify different degrees of difficulty. In the United Kingdom, severe cases are thought to occur in $7 \%$ of primiparous births (Mee, 2008) but rates of assisted calvings are much higher, reaching about 16\% nationally (Wall et al., 2010). Not only does calving difficulty increase farm workload, it also has adverse effects on the subsequent survival, health, and performance of mothers and offspring (Dematawewa and Berger, 1997; Lombard et al., 2007; Tenhagen et al., 2007). For a review on effects and risk factors of dystocia, see Mee (2008). Thus, calving difficulty raises productivity, economic, and animal welfare issues.

It has been shown that calving difficulty reduces milk yield in the cow. It is not clear, however, how long the adverse effect on milk production lasts. In fact, although some authors seem to find a deleterious effect on the overall lactation of cows (Mangurkar et al., 1984; Djemali et al., 1987; Dematawewa and Berger, 1997), some studies suggest shorter term effects that disappear beyond 14 DIM (Rajala and Grohn, 1998), 90 DIM (Thompson et al., 1983), or 6 mo postpartum (Tenhagen et al., 2007). Furthermore, the degree of difficulty at which milk losses are reported ranges from slight degrees of difficulty (Djemali et al., 1987; Dematawewa and Berger, 1997) to only in severe cases when surgery is needed (Tenhagen et al., 2007). Additionally, losses are thought to be greater with increasing degrees of difficulty (Djemali et al., 1987; Dematawewa and Berger, 
1997). However, the pattern with which milk losses vary is not always obvious (e.g., Mangurkar et al., 1984) and other factors such as the overall yield or parity of the cow (Rajala and Grohn, 1998) might influence it. The underlying reasons for such variation could be attributed to a range of factors such as different scoring methods, animal genetics, livestock management, calving management, or even evaluation methods.

Using milk production to assess the performance of dairy cows is straightforward and can be seen as being related to the income of dairy producers. This animaloriented approach, combined with other indicators, can give some insight into the welfare of the animal, because milk yields are known to be lowered in the event of stress (Hasegawa et al., 1997; Bruckmaier and Blum, 1998) or disease because of the redistribution of energy requirements in favor of the immune system (Rajala and Grohn, 1998; Bareille et al., 2003). The use of data sets that contain animals with full lactations only or that have achieved a certain stage of lactation seems to be common practice when calculating effects of calving difficulty on milk production (Mangurkar et al., 1984; Djemali et al., 1987).

However, dystocial animals are more likely to die or be culled in the early stages of their lactation (Tenhagen et al., 2007; Dobson et al., 2008). Therefore, restriction on lactation length could introduce bias in the results. Consequently, taking into account the whole herd, whatever the lactation stage each animal actually achieves, seems preferable to represent the milk losses that producers incur.

Furthermore, the use of such data sets usually implies extrapolating the milk production from animals to which daily continuous records are not known (such as test-day yields). Because milk production is decreased during a sickness episode, if sampling occurs at or near that episode, the extrapolation of a cow's milk production can consequently give a biased estimation of her total yields. Unfortunately, dystocial cows are known to be more likely to suffer from diseases (Thompson et al., 1983; Benzaquen et al., 2007). Therefore, such cases are more likely to occur and bias to arise in dystocial animals.

Although saleable milk yield is related to the animal's milk production, it can account for additional losses due to diseases and their treatment, such as medication requiring a specific milk withdrawal period (e.g., a mastitis episode requiring antibiotic treatment when the milk produced cannot be sold commercially).

Taking the producer's perspective by assessing cumulative saleable milk yields, regardless of each animal achieving a full lactation, could address both concerns. In fact, such an approach at the herd level can take into account the losses due to animals that suffer from diseases or leave the herd early (Figure 1). Animals that suffer from diseases may have lowered or null saleable yields for a short period, whereas cows leaving the herd early do not provide any more saleable milk. Additionally, such a method reflects the dairy producer's true income.

The objective of the study was to investigate how various degrees of calving difficulty would alter the production of saleable milk of UK dairy cattle over different stages of their subsequent lactation as well as their estimated milk production.

\section{MATERIALS AND METHODS}

\section{Animals, Housing, and Management}

Data from lactating animals were obtained from the Scottish Agricultural College experimental HolsteinFriesian dairy herd (Scotland, United Kingdom). This herd was managed in accordance with the UK regulations on animal care and ethics of experimental animals. Following a long-term genetic breeding and feeding system project, animals were from 2 genetic groups (animals selected toward greater milk solids production and animals selected to be the rolling UK average) and split over 2 diet types (high-forage and low-forage diets; Pryce et al., 1999; Bell and Roberts, 2007). Cows from both genetic groups that were not on this long-term trial were fed commercial diets of low-forage types. The herd was managed from 1990 to 2001 inclusive at the University of Edinburgh near Edinburgh (hereafter, the Edinburgh herd) where it was shared with their veterinary school, and was then moved to the Scottish Agricultural College dairy research center at the Crichton Royal Farm in Dumfries (the Crichton herd), where it was managed from 2002 onward.

The Edinburgh herd was milked twice a day and the diets were formulated to contain approximately 1,500 and $2,500 \mathrm{~kg}$ of concentrate per lactation for the highand low-forage diets, respectively, representing average practice usage in the UK. Nontrial cows were fed a diet similar to the low-forage diet.

The Crichton herd was managed in 2 contrasting management systems, with one group kept indoors on a low-forage diet and the other group fed a home-grown, high-forage diet with summer grazing. Nontrial cows were fed a nontrial diet similar to the low-forage diet. The Crichton herd was milked 3 times daily from 2003 onward.

In both herds, calving difficulty was scored as follows: $\mathbf{N}=$ no assistance; $\mathbf{F N} / \mathbf{F M}=$ farm assistance without/with malpresentation of the calf; $\mathbf{V N} / \mathbf{V M}=$ 

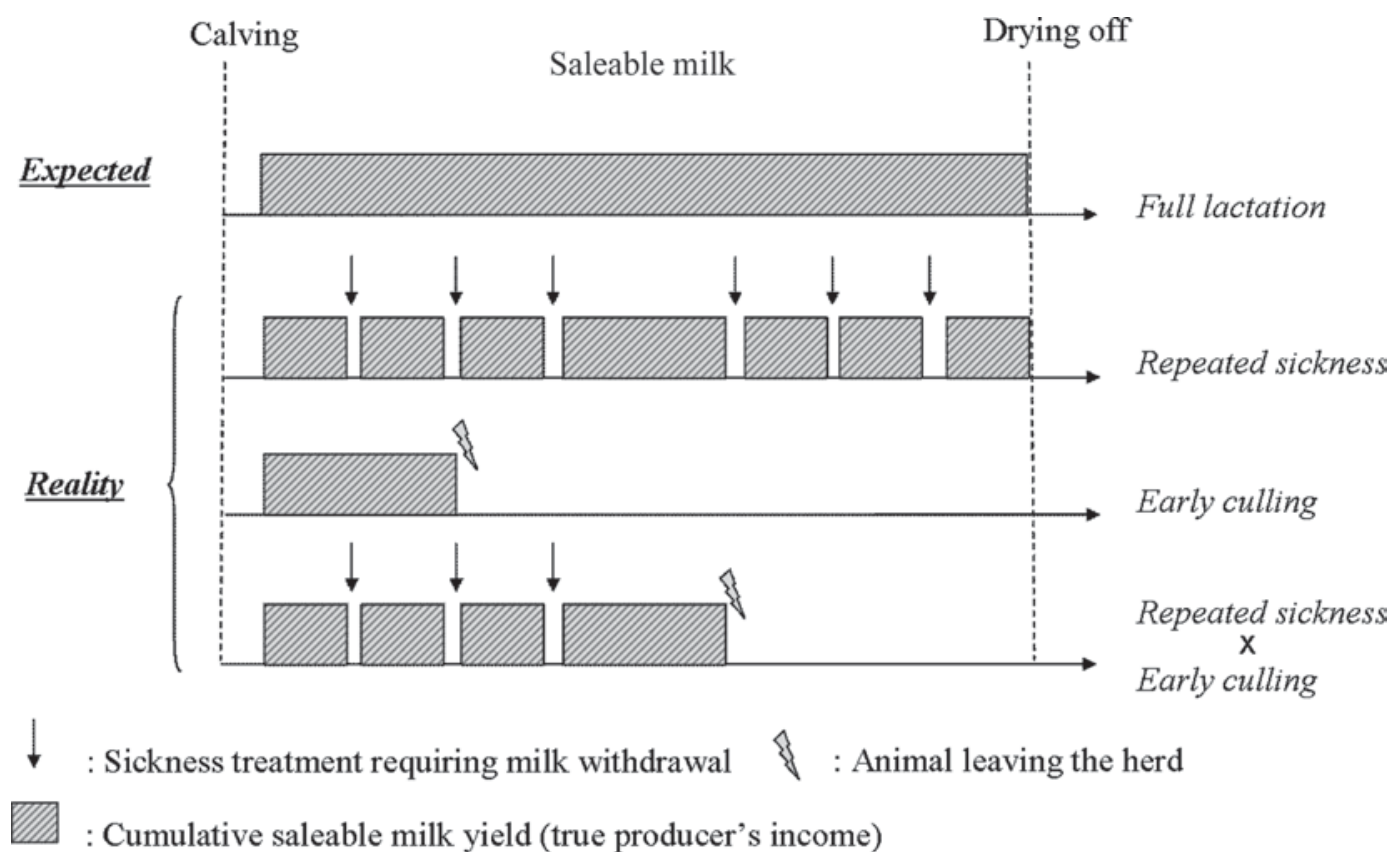

Figure 1. Representation of the saleable milk production of an individual dairy cow over her lactation either as expected to be achieved over a full lactation or actually produced (reality). Unlike expectations, in reality, milk cannot always be sold when some treatments for sickness occur that require a milk withdrawal period. Moreover, when the cow leaves the herd, production of saleable milk will stop. A combination of the above scenarios can also happen. For each individual cow, at any point in her lactation stage (achieved or not), the cumulative saleable milk produced is more representative of the income she provides to her keeper rather than what could have been expected.

veterinarian assistance without/with malpresentation of the calf; and $\mathbf{V C}=$ caesarean section.

\section{Data Set Description}

Data on individual cows lactations were obtained from the farm's database. Data were extracted on the condition that a calving difficulty score was available, the cow had not aborted, and the lactation number was $\leq 10$. No restriction was made on a minimum lactation length for the reasons stated above. Prevalence and causes of dystocia may differ among parities, with higher difficulty rates and predominance of cases of feto-pelvic incompatibility in primiparous animals (Mee, 2008). However, the aim of the study was to look at the effects of different degrees of difficulty on milk production at the herd level, regardless of how the difficulty arose, and therefore, animals from both parities were included.

Lactation yield data of animals having calved from 1990 to 2001 inclusive and from 2003 to August 20, 2009, only were included so that for each herd, all animals would have the same management background, and the transition period between sites was excluded. The data set therefore contained data on 3,843 lactations: 2,430 in the Edinburgh herd completed by 898 animals and 1,413 in the Crichton herd completed by 555 animals (Table 1 ).

For each lactation of each cow, characteristics such as cow identity, parity (primiparous vs. multiparous),

Table 1. Number of lactations per calving difficulty score (relative proportion of scores, $\%$, in parentheses) for both Edinburgh and Crichton herds

\begin{tabular}{lccccccc}
\hline & \multicolumn{7}{c}{ Calving difficulty } \\
\cline { 2 - 5 } Herd & $\mathrm{N}$ & $\mathrm{FN}$ & $\mathrm{FM}$ & $\mathrm{VN}$ & $\mathrm{VM}$ & $\mathrm{VC}$ & Total \\
\hline Edinburgh & 1,986 & 265 & 84 & 44 & 33 & 18 & 2,430 \\
$\begin{array}{l}\text { (n=898) } \\
\text { Crichton }\end{array}$ & $(81.7)$ & $(10.9)$ & $(3.5)$ & $(1.8)$ & $(1.4)$ & $(0.7)$ & \\
$(\mathrm{n}=555)$ & 1,188 & 170 & 36 & 6 & 8 & 5 & 1,413 \\
\hline
\end{tabular}

${ }^{1} \mathrm{~N}=$ no assistance; $\mathrm{FN} / \mathrm{FM}=$ farm assistance without/with malpresentation; $\mathrm{VN} / \mathrm{VM}=$ veterinarian assistance without/with malpresentation; $\mathrm{VC}=$ caesarean section. 
genetic group, diet fed during the lactation, calving season (summer: April to September; winter: October to March), calving year, age at calving (mo), sire of the cow, and calving difficulty scores were extracted from the database. Birth weight of the newborn, sex of the calf, calving weight, and calving condition score of the dam at parturition were not considered as candidates to be included in the statistical model. The reason for this is that our interest was on the effect of calving difficulty in its own right. Those variables are known to be confounded with calving difficulty in the literature (Meijering, 1984; Mee, 2008) and this was checked in our study by using data plots and looking at the variation shared if forced into the models.

\section{Milk Production Data: Saleable Milk Yields and Cow's Milk Production}

In both herds, individual daily milk production was recorded automatically at milking conditional on the milk being sent to the tank for sale and, therefore, considered as being saleable milk.

Cumulative saleable milk yield (SMY, L) was calculated at different stages of the lactation of interest: 30, 60,90 , and 300 DIM. Saleable milk yield was calculated regardless of each animal having achieved each of these stages to account for the amount of milk the producer was actually able to sell within each period. As shown in Figure 1, calculations of SMY were performed by summing the daily amount of milk sent to the tank during those periods, the amount being null when the milk was not saleable because of a medical treatment or from the death or culling of the animal onward when applicable. Lactation SMY were obtained based on the real lactation length achieved by the animal (rather than truncating at 305 DIM). Saleable milk yields were used to reflect a producer's perspective.

To reflect on the cow's perspective, the average daily amount of milk produced by the dam, referred to as cow's milk production (CMP), was used. For each of the lactation stages of interest, this was calculated as being the ratio between the cumulative SMY during that period and the number of days when milk was sent to the tank during the same period. Data from 2,239 and 1,325 lactations were available for analysis of both the cumulative SMY and daily mean yields in the Edinburgh and Crichton herds, respectively.

Because of the data extraction process, some of the cows from the Edinburgh herd appeared in our data set with artificially truncated lactation implied by the cut-off point of 2002. Therefore, their milk production data were accounted for only until the lactation stage of interest preceding the truncation. Therefore, this led to a slight decline in numbers of lactation available toward later lactation stages.

\section{Statistical Analyses}

Data from both herds were analyzed separately. It was decided to keep the 2 herds separate for the analysis instead of accounting for a herd effect. In fact, because most of the animals had been transferred from Edinburgh to Crichton, the 2 herds cannot be seen as fully independent and therefore do not comply with the underlying statistical hypothesis of independence of the variables. Furthermore, management practice at calving, especially the threshold for intervention, seemed to be different in the 2 herds, with a higher propensity of the farm staff to provide assistance at calving and to call for a veterinarian in the Edinburgh herd, where the facilities were shared with the University of Edinburgh Veterinary School (Table 1).

Linear mixed models were applied following a REML procedure in Genstat (11th ed., 2008, VSN International Ltd., Hemel Hempstead, UK) using forward-stepwise logistic regression models (Hosmer and Lemeshow, 2000) as described in previous studies (Haskell et al., 2009; Rutherford et al., 2009). The random model chosen included the cow identity nested within its sire. All variables were treated as fixed effects (factors), whereas age at calving (age) and calving year were treated as continuous variables. Age at calving did not show a linear relationship with milk yields and could not be included as such in the model. However, it showed 2 distinct linear trends for each parity and thus, age at calving was centered on the relevant parity's mean for each lactation (age-C).

An individual model was built for each herd and stage of lactation. Each variable was tested independently as a univariate and became a candidate for the multivariable model if it had a $P$-value $<0.25$. The variables tested as univariates were parity, genetic group, diet, season, year of calving, age at calving, and calving difficulty. The candidate variables were then added into the multivariable model using stepwise selection techniques with the most significant variables with the highest Wald statistic being added first. Candidate variables were kept in the model with significance attributed at $P<0.05$ (when all other explanatory variables in the models had been fitted), and calving difficulty was always forced in the model and fitted at the end. Interactions were tested once the whole model was set up. This included calving difficulty interacting with, respectively, genetic group, diet, parity, and year, as well as the interaction between year and month, genetic group, and diet as well as parity and age. Finally, normality of the residuals 
Table 2. Estimated means of the cumulative saleable milk yields ( $\mathrm{L} \pm \mathrm{SEM}$ ) at 30,60, 90, and 300 DIM and over the completed subsequent lactation of dairy cattle from the Edinburgh herd following different degrees of calving difficulty

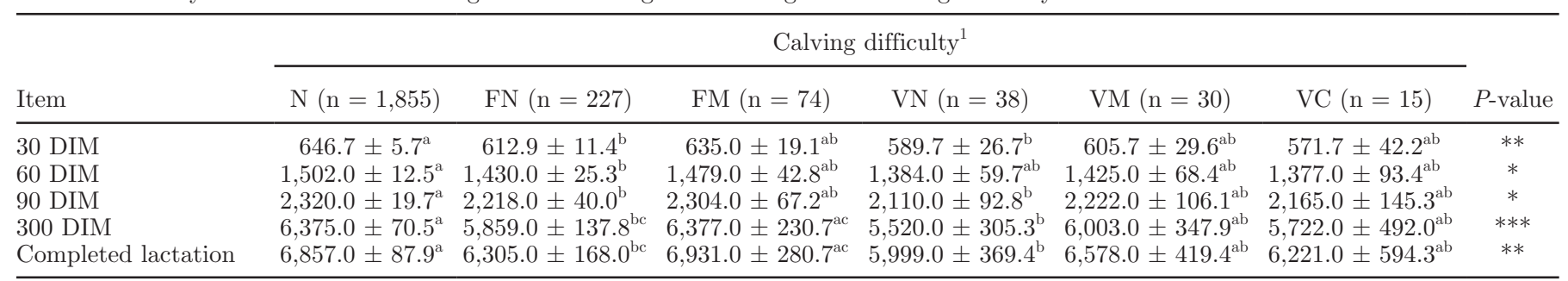

${ }^{\mathrm{a}-\mathrm{c}}$ Within a row, means with different superscripts differ $(P<0.05)$.

${ }^{1} \mathrm{~N}=$ no assistance; FN/FM = farm assistance without/with malpresentation; VN/VM = veterinarian assistance without/with malpresentation; $\mathrm{VC}=$ caesarean section. The number of lactations available for analysis for each calving difficulty score is given in parentheses.

${ }^{*} P<0.05 ;{ }^{* *} P<0.01 ;{ }^{* * *} P<0.001$.

was verified. Initially, new models were built for each stage of lactation and outcome considered. However, the contributing factors were very similar for the same outcome measure at each stage of lactation. Therefore, for purposes of clarity, only one model was retained and used to analyze an outcome measure throughout the stages of lactation. These models are presented below:

$$
\begin{aligned}
& S M Y=\mu+\text { parity }+ \text { genetic } \times \text { diet }+ \text { year } \\
& + \text { season }+C D+\varepsilon(\text { Edinburgh herd }), \\
& C M P=\mu+\text { parity }+ \text { genetic }+ \text { diet }+ \text { year } \\
& + \text { season }+C D+\varepsilon(\text { Edinburgh herd }),
\end{aligned}
$$

$$
\begin{aligned}
S M Y= & \mu+\text { parity } \times \text { age }-C+\text { year }+ \text { diet }+ \text { genetic } \\
& + \text { season }+C D+\varepsilon(\text { Crichton herd }),
\end{aligned}
$$$$
C M P=\mu+\text { parity } \times \text { age }-C+\text { diet }+ \text { genetic }
$$$$
+ \text { year }+ \text { season }+C D+\varepsilon(\text { Crichton herd }),
$$

where $\mu=$ the overall population mean, $C D=$ calving difficulty, and $\varepsilon=$ the random residual effect.

Considering the few lactations available for the higher degrees of difficulty, the analysis was also run grouping the veterinarian-assisted scores together in a single category (Edinburgh herd: $\mathrm{n}=83$; Crichton herd: $\mathrm{n}=$ $15)$.

\section{RESULTS}

\section{SMY}

Edinburgh Herd. Parity, genetic group, diet, and calving year affected saleable yields at all stages of the lactation except at 30 DIM for calving season and at both 300 DIM and over the total lactation for genetic group interacting with diet. Cows experiencing FN and VN scores had decreased cumulative SMY throughout lactation compared with unassisted animals $(P$ $<0.05$; Table 2). Losses occurred as early as 30 DIM (FN: $-5.2 \%$; VN: $-8.8 \%$ ) and persisted until the end of the lactation (FN: $-8.1 \%$; VN: $-12.5 \%$ ). No losses were found for FM, VM, and VC births. Grouping the veterinarian-assisted scores together did not alter the significance of the analysis.

Crichton Herd. Parity interacting with age-C, calving year, diet, genetic group, and calving season were significant at all stages of lactation except for calving season over the lactation. Calving difficulty resulted in decreased SMY $(P<0.05$; Table 3$)$ for the FM and VC births (FM: $-12.4 \%$; VC: $-42.8 \%$ ) compared with unassisted animals only during the first 30 DIM. No significant effect was found at other stages of lactations. Grouping the veterinarian-assisted scores together did not alter the significance of the analysis.

\section{CMP}

Edinburgh Herd. Cow's milk production was affected by parity, diet, genetic group, calving year, and calving season throughout all stages of lactation tested except that the effect of calving season disappeared from 300 DIM onward. Calving difficulty did not affect CMP $(P>0.05$; Table 4$)$ at any stage of lactation. A reduction in production of $1.7 \mathrm{~L} / \mathrm{d}$ was observed at 30 $\operatorname{DIM}(P=0.025)$ and of $1.6 \mathrm{~L} / \mathrm{d}$ at $60 \operatorname{DIM}(P=0.049)$ for the veterinarian-assisted scores grouped together (n $=83$ ) compared with the unassisted animals.

Crichton Herd. Cow's milk production was affected by parity interacting with age-C, diet, genetic group, calving year, and calving season throughout the stages of lactation tested, except that the effect of parity interacting with age-C disappeared from 300 DIM onward. Compared with unassisted animals, calving difficulty was associated with a decrease in the CMP for FM 
Table 3. Estimated means of the cumulative saleable milk yields ( \pm SEM) at 30, 60, 90, and 300 DIM and over the completed subsequent lactation of dairy cattle from the Crichton herd following different degrees of calving difficulty

\begin{tabular}{lccccccc}
\hline & \multicolumn{5}{c}{ Calving difficulty $^{1}$} \\
\cline { 2 - 6 } Item & $\mathrm{N}(\mathrm{n}=1,111)$ & $\mathrm{FN}(\mathrm{n}=163)$ & $\mathrm{FM}(\mathrm{n}=36)$ & $\mathrm{VN}(\mathrm{n}=3)$ & $\mathrm{VM}(\mathrm{n}=8)$ & VC $(\mathrm{n}=4)$ & $P$-value \\
\hline 30 DIM & $658.9 \pm 10.5^{\mathrm{a}}$ & $642.0 \pm 18.6^{\mathrm{a}}$ & $577.3 \pm 124.3^{\mathrm{bc}}$ & $489.6 \pm 124.3^{\mathrm{abc}}$ & $607.5 \pm 76.0^{\text {abc }}$ & $376.6 \pm 107.9^{\mathrm{c}}$ & $*$ \\
60 DIM & $1,510.0 \pm 25.8$ & $1,506.0 \pm 44.0$ & $1,406.0 \pm 85.4$ & $1,384.0 \pm 59.7$ & $1,067.0 \pm 289.0$ & $1,197.0 \pm 251.3$ & NS \\
90 DIM & $2,304.0 \pm 42.2$ & $2,326.0 \pm 71.7$ & $2,242.0 \pm 138.7$ & $1,619.0 \pm 469.0$ & $2,478.0 \pm 286.4$ & $2,028.0 \pm 408.8$ & NS \\
300 DIM & $6,462.0 \pm 147.8$ & $6,759.0 \pm 243.3$ & $6,658.0 \pm 464.1$ & $4,302.0 \pm 1,563.5$ & $5,978.0 \pm 955.0$ & $6,571.0 \pm 1,361.2$ & NS \\
Completed lactation & $7,293.0 \pm 189.2$ & $7,700.0 \pm 302.8$ & $7,466.0 \pm 569.6$ & $4,267.0 \pm 1,911.5$ & $6,443.0 \pm 1,165.2$ & $6,841.0 \pm 1,672.4$ & NS
\end{tabular}

${ }^{\mathrm{a}-\mathrm{c}}$ Within a row, means with different superscripts differ $(P<0.05)$.

${ }^{1} \mathrm{~N}=$ no assistance; FN/FM = farm assistance without/with malpresentation; VN/VM = veterinarian assistance without/with malpresentation; $\mathrm{VC}=$ caesarean section. The number of lactations available for analysis for each calving difficulty score is given in parentheses.

$* P<0.05$.

and VC scores of 7.8 and $25.3 \%$, respectively (Table 5 ), at 30 DIM. A decrease of 34.4, 31.1, and $28.5 \%$ of the cow's yields for the VN scores was observed at 30, 60, and 90 DIM, respectively. No effect beyond 90 DIM was shown for any other score of calving difficulty. Grouping the veterinarian-assisted scores together did not alter the significance of the analysis.

\section{DISCUSSION}

\section{Detrimental Effects of Calving Difficulty on CMP and SMY}

Calving difficulty resulted in decreased saleable milk production in both herds but a decrease in CMP was not observed in the Edinburgh herd. However, the increasing variability in CMP over the scores may have masked such an effect. In fact, when variation was reduced by grouping the veterinarian-assisted scores together, this group of animals then had decreased production up to 60 DIM compared with the unassisted animals. A reduction in the milk production of cows experiencing difficulty at parturition is in line with previous studies (Mee, 2008). It is therefore not surprising that SMY were also lowered, probably because of decreased CMP as well as higher odds of being culled or suffering from diseases in dystocial animals (Tenhagen et al., 2007; Dobson et al., 2008).

Impairment of performance following a difficult calving is mainly attributed to the experience of an increased length of labor (Doornbos et al., 1984) and its implications on adrenocortical function (Hudson et al., 1976; Nakao and Grunert, 1990; Civelek et al., 2008). This could lead to decreased yields in the dams (Dobson et al., 2001). Moreover, such hormonal changes depress their immune system, which, along with higher risks of bacterial contamination during assistance (Dohmen et al., 2000), may increase the animal's susceptibility to disease. Additionally, underlying conditions that put dams at risk of dystocia such as inappropriate BCS, poor nutrition over the dry period, and hormonal imbalances might be partly responsible for decreased yields by the animals and affect the development of the udder before the start of the lactation (Banos et al., 2007; Berry et al., 2007; Roche et al., 2009).

Decreased milk production from the dams could also result from lower feed intake postcalving. Although a recent study in dairy cattle did not find differences in DMI between eutocial and dystocial during the first 2 d postcalving (Proudfoot et al., 2009), a study on beef cattle showed that cows having delivered by caesarian section spent less time eating than cows having delivered

Table 4. Estimated means of the cow's milk production (L/d \pm SEM) at 30, 60, 90, and 300 DIM and over the completed subsequent lactation of dairy cattle from the Edinburgh herd following different degrees of calving difficulty

\begin{tabular}{|c|c|c|c|c|c|c|c|}
\hline Item & \multicolumn{6}{|c|}{ Calving difficulty $^{1}$} & $P$-value \\
\hline 30 DIM & $26.81 \pm 0.16$ & $26.52 \pm 0.34$ & $26.70 \pm 0.57$ & $24.51 \pm 0.79$ & $25.79 \pm 0.88$ & $25.51 \pm 1.26$ & $\dagger$ \\
\hline 90 DIM & $28.59 \pm 0.19$ & $28.44 \pm 0.36$ & $28.37 \pm 0.60$ & $26.26 \pm 0.83$ & $28.02 \pm 0.95$ & $27.53 \pm 1.30$ & NS \\
\hline 300 DIM & $24.14 \pm 0.17$ & $24.17 \pm 0.30$ & $24.11 \pm 0.49$ & $23.36 \pm 0.65$ & $23.68 \pm 0.73$ & $23.49 \pm 1.04$ & NS \\
\hline Completed lactation & $23.42 \pm 0.16$ & $23.56 \pm 0.29$ & $23.19 \pm 0.48$ & $23.04 \pm 0.63$ & $23.17 \pm 0.72$ & $22.71 \pm 1.02$ & NS \\
\hline
\end{tabular}

${ }^{1} \mathrm{~N}=$ no assistance; $\mathrm{FN} / \mathrm{FM}=$ farm assistance without/with malpresentation; VN/VM = veterinarian assistance without/with malpresentation; $\mathrm{VC}=$ caesarean section. The number of lactations available for analysis for each calving difficulty score is given in parentheses.

$\dagger P<0.10$. 
Table 5. Estimated means of the cow's milk production (L/d \pm SEM) at 30, 60, 90, and 300 DIM and over the completed subsequent lactation of dairy cattle from the Crichton herd following different degrees of calving difficulty

\begin{tabular}{|c|c|c|c|c|c|c|c|}
\hline \multirow[b]{2}{*}{ Item } & \multicolumn{6}{|c|}{ Calving difficulty ${ }^{1}$} & \multirow[b]{2}{*}{$P$-value } \\
\hline & $\mathrm{N}(\mathrm{n}=1,111)$ & $\mathrm{FN}(\mathrm{n}=163)$ & $\mathrm{FM}(\mathrm{n}=36)$ & $\mathrm{VN}(\mathrm{n}=3)$ & $\mathrm{VM}(\mathrm{n}=8)$ & $\mathrm{VC}(\mathrm{n}=4)$ & \\
\hline 30 DIM & $29.46 \pm 0.28^{\mathrm{a}}$ & $28.85 \pm 0.51^{\mathrm{a}}$ & $27.15 \pm 0.99^{\mathrm{b}}$ & $19.32 \pm 3.37^{\mathrm{b}}$ & $28.70 \pm 2.05^{\mathrm{a}}$ & $22.02 \pm 2.98^{\mathrm{b}}$ & $* * *$ \\
\hline 60 DIM & $31.32 \pm 0.30^{\mathrm{a}}$ & $31.09 \pm 0.50^{\mathrm{a}}$ & $29.61 \pm 0.97^{\mathrm{a}}$ & $21.57 \pm 3.27^{\mathrm{b}}$ & $30.32 \pm 1.97^{\mathrm{a}}$ & $26.12 \pm 2.93^{\mathrm{ab}}$ & * \\
\hline 90 DIM & $31.55 \pm 0.30^{\mathrm{a}}$ & $31.39 \pm 0.49^{\mathrm{a}}$ & $30.05 \pm 0.94^{\mathrm{a}}$ & $22.57 \pm 3.16^{\mathrm{b}}$ & $30.52 \pm 1.89^{\mathrm{a}}$ & $27.25 \pm 2.88^{\mathrm{ab}}$ & $*$ \\
\hline 300 DIM & $28.94 \pm 0.31$ & $29.08 \pm 0.46$ & $27.81 \pm 0.82$ & $24.10 \pm 2.74$ & $26.90 \pm 1.63$ & $25.91 \pm 2.55$ & NS \\
\hline Completed lactation & $28.31 \pm 0.31$ & $28.36 \pm 0.47$ & $27.17 \pm 0.85$ & $23.39 \pm 2.82$ & $26.45 \pm 1.69$ & $25.48 \pm 2.58$ & NS \\
\hline
\end{tabular}

${ }^{\mathrm{a}, \mathrm{b}}$ Within a row, means with different superscripts differ $(P<0.05)$.

${ }^{1} \mathrm{~N}=$ no assistance; $\mathrm{FN} / \mathrm{FM}=$ farm assistance without/with malpresentation; VN/VM = veterinarian assistance without/with malpresentation; $\mathrm{VC}=$ caesarean section. The number of lactations available for analysis for each calving difficulty score is given in parentheses.

$* * * P<0.001 ; * P<0.05$.

naturally during the first $3 \mathrm{~d}$ postpartum (Kolkman et al., 2010). It is very likely that the increased occurrence of sickness during the subsequent lactation may lower their appetite more often. Dystocial cows might experience greater postpartum pain (Barrier et al., 2010) as a result of the traction and associated trauma of the tissues and possible inflammations of the reproductive tract, which in turn, may lower their feed intake.

\section{Effects of Calving Difficulty Diverged Between the Herds}

In our study, although impairment in CMP and SMY was found in both herds, the scores and stages of lactation affected were not the same within the 2 herds. In our study, the scale used to rate difficulty at calving was similar between both herds and it is unlikely that our definitions led to inconsistency of scoring within the years. The level of supervision at calving and the propensity to assist can vary between farms, reflecting sociological factors (Dargatz et al., 2004). It is believed that the threshold for intervention and for calling a veterinarian was lower in the Edinburgh herd than in the Crichton herd, certainly because the former was co-managed by the veterinary school. As such, a VN calving in Edinburgh could have been scored as an FN calving in Crichton. Other factors such as how assistance was performed, the pre- and postcalving care, as well as the overall management of the herd in terms of housing and milking routine could have caused variation in the effects of a difficult calving. Divergences within the 2 herds were also highlighted in terms of what factors affected milk yields when the statistical models were constructed.

Considering CMP, no decrease was found in the Edinburgh herd, whereas the Crichton herd suffered losses for FM, VN, and VC births. Because estimations for the VN and VC scores relied on only a few lactations, evidence from other studies would be needed to support this result. Nonetheless, when grouped together, the animals with veterinarian-assisted scores showed significantly lower CMP until 90 DIM. The FM dams did not carry over the detrimental effect on CMP for as long as the VN dams, whereas the VM dams did not suffer losses compared with the other veterinarian-assisted dams. Although malpresentation of the newborn can be thought of as increasing the difficulty of the delivery, it is possible that this occurrence is spotted earlier because of the calf being stuck early in the birth canal or by the nonappearance of the feet. Early diagnosis and assistance could then shorten the labor length, thus diminishing the detrimental effects of prolonged labor on milk production.

In regards to SMY, in the Edinburgh herd, FN and VN cows had decreased SMY throughout the lactation, whereas losses occurred in the Crichton herd for the FM and VC cows only in the first 30 DIM. In both herds, lack of effects on SMY for some of the veterinarianassisted scores might relate to the few data points available for the analysis, and the dramatic loss found for VC scores in the Crichton herd should be treated with caution for similar reasons. In the Edinburgh herd, the absence of an effect in FM scores on SMY is in line with the absence of a reduction in CMP for this score and might be explained similarly by the shortened labor length. In contrast, FM animals in the Crichton herd showed losses in SMY. This finding could be attributed to lower CMP or the additional manipulation of the calf might have resulted in increased odds of contracting an infection (Dohmen et al., 2000). This may explain why, relative to unassisted animals, losses were much steeper in SMY than in CMP, with a $12.4 \%$ decrease in the former and $7.4 \%$ in the latter.

Furthermore, in contrast to the Edinburgh herd, where SMY losses were predominant throughout the lactation, SMY losses were not evident in the Crichton herd after 30 DIM. It is possible that the care and subsequent management of the dystocial dams in the 
Crichton herd was more favorable for the dams to recover from a difficult calving. However, this idea would not be supported by the hypothesis drawn earlier on FM dams. Furthermore, the 3-times-a-day milking in the Crichton herd compared with twice-a-day milking in Edinburgh may have contributed to the dilution of milk losses over time. In fact, a 1-L reduction in milk production corresponds to an inferior proportional loss when yields are higher. A larger data set may have helped to show significance if an effect after 30 DIM exists.

As discussed in detail above, our results support the idea that the way the herd is managed influences how difficulty at calving will affect the performance of the cow in terms of both subsequent cow's yields and cumulative saleable yields.

\section{SMY Best Reveal the Economic Shortfall to the Producers and Might Indicate Long-Lasting Biological Stresses in Dystocial Cows}

Despite the differences within herds, using CMP or SMY to assess effects of calving difficulty actually resulted in different effects being shown. This shows that these 2 methods are distinct from each other. In fact, CMP gives insight into the subsequent production by the animal itself, whereas SMY of the whole herd will additionally account for the wasted milk and the absence of saleable milk for the animals that leave the herd and therefore be more representative of farmers' losses. It is therefore not surprising that cumulative SMY were able to show more deleterious effects than CMP alone. For example, no effect of calving difficulty on CMP was observed in the Edinburgh herd (Table 4), whereas SMY were decreased for FN and VN dams. Moreover, SMY losses could be shown at the lactation level when analysis of SMY revealed no significant losses even in early lactation. It is tempting to infer that the deeper effect reported using SMY compared with CMP could be health-related or due to the early culling or death of the dystocial animals. However, although culling rates and morbidity are higher for cows experiencing difficulty at calving (Thompson et al., 1983; Benzaquen et al., 2007; Tenhagen et al., 2007; Dobson et al., 2008), further investigation into the health and survival data of the 2 herds would help reach a firmer conclusion in this particular study.

Therefore, using cumulative SMY on the whole herd rather than CMP could reveal greater shortfall to the producer because it can account for some of the disease and culling costs. It was not the aim of the study to provide an economic analysis of the herd, which would need to be multifactorial. However, to illustrate the income loss experienced by the producer, extrapolation of the results obtained on SMY from the Edinburgh herd would mean a shortfall of around $\$ 3,250 / \mathrm{yr}$ for the average UK dairy farm (considering an average farm with 112 lactating animals, a milk price of 24 pence/L, and $£ 1=\$ 1.6$ ) in terms of income drawn from milk sales.

As explained above, a loss of SMY calculated on the whole herd indicates decreased production by the animals, health issues, animals leaving the herd, or a combination of these. To that extent, SMY also indicate better the biological stresses that the dystocial animal might encounter during the subsequent lactation than CMP alone.

Therefore, considering the economic shortfall to dairy producers and the deleterious effects on the cow, using saleable milk production of the whole herd seems to be an attractive approach for improvements to be made. On the other hand, some practicalities should not be ignored and it would be not only very challenging but also very costly to collect such data on a larger scale. Furthermore, from a statistical point of view, the study of CMP resulted in less intrinsic variation in the data than SMY and therefore it is easier to pick up existing differences in the former. Nonetheless, the analysis of the cumulative saleable yield of the whole herd best reflected the producer's losses following a difficult calving and seemed to better address the occurrence of long-lasting biological stresses that can be related to animal welfare.

\section{CONCLUSIONS}

Calving difficulty was found to impair the milk production of dairy cows and production of saleable milk, resulting in reduced income for dairy producers as well as detrimental effects to the cows. Looking at cumulative saleable milk yields of the whole herd, independently of each animal having achieved a full lactation, might give a more sensitive picture of what is happening to the cow and as such, might reflect more accurately the underlying biological stresses experienced by the animals. Finally, herd management clearly influenced the magnitude and duration of the effects and at which degree of difficulty adverse effects were found. Alleviating difficulty at calving through good herd management practice before, during, and after parturition, as well as genetic improvement of the animals, should therefore benefit both dairy herds and producers.

\section{ACKNOWLEDGMENTS}

The authors are grateful to Defra (London, UK), the Scottish Government (Edinburgh, UK), CIS (Rickmansworth, UK), Cogent (Aldford, UK), DairyCo (Ke- 
nilworth, UK), Genus (Nantwich, UK), Holstein UK (Rickmansworth, UK), and NMR (Chippenham, UK) for funding under the Sustainable Livestock Production LINK Programme. Farm and technical staff are acknowledged for data collection over those years as well as Ian Nevison (BIOSS, UK) for the statistical support provided. C. M. Dwyer (Scottish Agriculture College, UK) and 2 anonymous reviewers are thanked for providing helpful comments that improved the quality of the manuscript.

\section{REFERENCES}

Banos, G., S. Brotherstone, and M. P. Coffey. 2007. Prenatal maternal effects on body condition score, female fertility, and milk yield of dairy cows. J. Dairy Sci. 90:3490-3499.

Bareille, N., F. Beaudeau, S. Billon, A. Robert, and P. Faverdin. 2003. Effects of health disorders on feed intake and milk production in dairy cows. Livest. Prod. Sci. 83:53-62.

Barrier, A. C., E. Ruelle, M. J. Haskell, and C. M. Dwyer. 2010. Effect of difficulty at calving on the subsequent vigour of the dairy calf, maternal behaviour of the dam and behavioural pain indicators. Page 52 in Proc. 14th Int. Conf. Prod. Dis. Farm Anim. Ghent, Belgium.

Bell, M. J., and D. J. Roberts. 2007. The impact of uterine infection on a dairy cow's performance. Theriogenology 68:1074-1079.

Benzaquen, M. E., C. A. Risco, L. F. Archbald, P. Melendez, M. J. Thatcher, and W. W. Thatcher. 2007. Rectal temperature, calving-related factors, and the incidence of puerperal metritis in postpartum dairy cows. J. Dairy Sci. 90:2804-2814.

Berry, D. P., J. M. Lee, K. A. Macdonald, and J. R. Roche. 2007. Body condition score and body weight effects on dystocia and stillbirths and consequent effects on postcalving performance. J. Dairy Sci. 90:4201-4211.

Bruckmaier, R. M., and J. W. Blum. 1998. Oxytocin release and milk removal in ruminants. J. Dairy Sci. 81:939-949.

Civelek, T., H. A. Celik, G. Avci, and C. C. Cingi. 2008. Effects of dystocia on plasma cortisol and cholesterol levels in Holstein heifers and their newborn calves. Bull. Vet. Inst. Pulawy 52:649-654.

Dargatz, D. A., G. A. Dewell, and R. G. Mortimer. 2004. Calving and calving management of beef cows and heifers on cow-calf operations in the United States. Theriogenology 61:997-1007.

Dematawewa, C. M. B., and P. J. Berger. 1997. Effect of dystocia on yield, fertility, and cow losses and an economic evaluation of dystocia scores for Holsteins. J. Dairy Sci. 80:754-761.

Djemali, M., A. E. Freeman, and P. J. Berger. 1987. Reporting of dystocia scores and effects of dystocia on production, days open and days dry from improvement herd data. J. Dairy Sci. 70:21272131.

Dobson, H., R. F. Smith, G. J. C. Bell, D. M. Leonard, and B. Richards. 2008. (Economic) costs of difficult calvings (in the UK dairy herd): How vets can alleviate the negative impact. Cattle Pract. $16: 80-85$

Dobson, H., J. E. Tebble, R. F. Smith, and W. R. Ward. 2001. Is stress really all that important? Theriogenology 55:65-73.

Dohmen, M. J. W., K. Joop, A. Sturk, P. E. J. Bols, and J. A. C. M. Lohuis. 2000. Relationship between intra-uterine bacterial contamination, endotoxin levels and the development of endometritis in postpartum cows with dystocia or retained placenta. Theriogenology 54:1019-1032.
Doornbos, D. E., R. A. Bellows, P. J. Burfening, and B. W. Knapp. 1984. Effects of dam age, prepartum nutrition and duration of labor on productivity and postpartum reproduction in beef females. J. Anim. Sci. 59:1-10.

Hasegawa, N., A. Nishiwaki, K. Sugawara, and I. Ito. 1997. The effects of social exchange between two groups of lactating primiparous heifers on milk production, dominance order, behavior and adrenocortical response. Appl. Anim. Behav. Sci. 51:15-27.

Haskell, M. J., F. M. Langford, M. C. Jack, L. Sherwood, A. B. Lawrence, and K. M. D. Rutherford. 2009. The effect of organic status and management practices on somatic cell counts on UK dairy farms. J. Dairy Sci. 92:3775-3780.

Hosmer, D. W., and S. Lemeshow. 2000. Applied Logistic Regression. 2nd ed. Wiley Inter-Science, New York, NY.

Hudson, S., M. Mullford, W. G. Whittlestone, and E. Payne. 1976. Bovine plasma corticoids during parturition. J. Dairy Sci. 59:744746.

Kolkman, I., S. Aerts, H. Vervaecke, J. Vicca, J. Vandelook, A. de Kruif, G. Opsomer, and D. Lips. 2010. Assessment of differences in some indicators of pain in double muscled Belgian Blue cows following naturally calving vs caesarean section. Reprod. Domest. Anim. 45:160-167.

Lombard, J. E., F. B. Garry, S. M. Tomlinson, and L. P. Garber. 2007. Impacts of dystocia on health and survival of dairy calves. J. Dairy Sci. 90:1751-1760.

Mangurkar, B. R., J. F. Hayes, and J. E. Moxley. 1984. Effects of calving ease-calf survival on production and reproduction in Holsteins. J. Dairy Sci. 67:1496-1509.

Mee, J. F. 2008. Prevalence and risk factors for dystocia in dairy cattle: A review. Vet. J. 176:93-101.

Meijering, A. 1984. Dystocia and stillbirth in cattle-A review of causes, relations and implications. Livest. Prod. Sci. 11:143-177.

Nakao, T., and E. Grunert. 1990. Effects of dystocia on postpartum adrenocortical function in dairy cows. J. Dairy Sci. 73:28012806.

Proudfoot, K. L., J. M. Huzzey, and M. A. G. von Keyserlingk. 2009. The effect of dystocia on the dry matter intake and behavior of Holstein cows. J. Dairy Sci. 92:4937-4944.

Pryce, J. E., B. L. Nielsen, R. F. Veerkamp, and G. Simm. 1999. Genotype and feeding system effects and interactions for health and fertility traits in dairy cattle. Livest. Prod. Sci. 57:193-201.

Rajala, P. J., and Y. T. Grohn. 1998. Effects of dystocia, retained placenta, and metritis on milk yield in dairy cows. J. Dairy Sci. 81:3172-3181.

Roche, J. R., N. C. Friggens, J. K. Kay, M. W. Fisher, K. J. Stafford, and D. P. Berry. 2009. Invited review: Body condition score and its association with dairy cow productivity, health, and welfare. J. Dairy Sci. 92:5769-5801.

Rutherford, K. M., F. M. Langford, M. C. Jack, L. Sherwood, A. B. Lawrence, and M. J. Haskell. 2009. Lameness prevalence and risk factors in organic and non-organic dairy herds in the United Kingdom. Vet. J. 180:95-105.

Tenhagen, B. A., A. Helmbold, and W. Heuwieser. 2007. Effect of various degrees of dystocia in dairy cattle on calf viability, milk production, fertility and culling. J. Vet. Med. A Physiol. Pathol. Clin. Med. 54:98-102.

Thompson, J. R., E. J. Pollak, and C. L. Pelissier. 1983. Interrelationships of parturition problems, production of subsequent lactation, reproduction, and age at first calving. J. Dairy Sci. 66:11191127.

Wall, E., R. Mrode, G. Banos, and M. Coffey. 2010. Development of calving-ease evaluations for UK Holstein-Friesian cows. Page 69 in Proc. BSAS and ARF. Br. Soc. Anim. Sci., Belfast, UK. 